\title{
Revictimización de niños y adolescentes tras denuncia de abuso sexual
}

\author{
Re-victimization of children and adolescents \\ after reporting sexual abuse
}

\author{
Marie-Astrid Dupret ${ }^{1}$ y Nathalia Unda ${ }^{2}$
}

\section{Resumen}

astrid.dupret@gmail.com

\begin{abstract}
El tema estudiado es el de la revictimización de menores después de la denuncia de un abuso sexual. Esta nueva vivencia de maltrato, se explica por las carencias de la atención por parte de las instituciones competentes, por falta de coordinación, por disfuncionamiento y, sobretodo, por desconocimiento del psiquismo infantil, de modo que la subjetividad de la víctima no está tomada en cuenta para orientar las acciones pertinentes, con consecuencias muy dañinas para ella. Después de analizar la palabra revictimización y su sentido específico en el ámbito institucional, se ilustrará este fenómeno con el recorrido de cuatro menores víctimas de abuso sexual a través el laberinto institucional. Por último, se investigarán los efectos desestructurantes sobre la subjetividad infantil de la revictimización institucional, y se propondrá algunas medidas para remediar a este problema acuciante.
\end{abstract}

\section{Palabras claves}

Violencia infantil, victimización, sustituciones, abuso sexual, silencio, formación profesional.

\begin{abstract}
The subject of research is the re-victimization of minors after a sexual abuse complaint is filed. This new experiencing of abuse can be explained by a lack of childcare services by relevant institutions, lack of coordination, inoperability and, particularly, ignorance around a child's psyche, that is, when the victim's subjectivity is not taken into account to guide the pertinent actions and which ends up having very harmful consequences for the child. After analyzing the word re-victimization and its particular meaning in an institutional setting, this phenomenon will be exemplified by walking through the experience of four victims of sexual abuse through the institutional labyrinth. Lastly, we will investigate the effects of deconstruction about a child's subjectivity and institutional re-victimization, and propose some measures to remediate this urgent problem.
\end{abstract}

Forma sugerida de citar: DUPRET, Marie-Astrid y Nathalia Unda (2013). "Revictimización de niños y adolescentes tras denuncia de abuso sexual”. En: Universitas, XI (19), juliodiciembre, p. 101-128. Quito: Editorial Abya Yala/Universidad Politécnica Salesiana.

1 Doctora, profesora Pontificia Universidad Católica. Psicoanalista miembro de la Asociación lacaniana Internacional. Profesora de Maestría en la Universidad Politécnica Salesiana.

2 Master en Política Pública de Infancia, Adolescencia (natalyaunda@yahoo.com) 


\section{Introducción}

En el Ecuador, el número elevado de situaciones de maltrato y abuso sexual contra los más jóvenes, así como la gravedad de la mayoría de los casos, es un tema tan doloroso como alarmante. Para solucionarlo, la única vía no solo recomendada sino ordenada por la ley, es la denuncia a alguna instancia del Estado. Sin embargo las carencias en la capacidad de intervención psicosocial y legal, lo vuelven más preocupante porque no raras veces el mismo abordaje institucional conduce a una revictimización de los menores, debido sobre todo a una ignorancia profunda de la estructura del pensamiento infantil y de su manera particular de experimentar e interpretar las actuaciones institucionales por las cuales pasa, en especial en el campo jurídico.

Como se verá a continuación, la revictimización es el resultado de la implementación de procedimientos de atención inadecuados que trazan una ruta llena de obstáculos, y que no respetan la vivencia penosa de la víctima, reactivando emociones negativas en relación con el delito y propiciando una repetición de la experiencia de violencia. La otra causa muy inquietante de revictimización, es la falta de coordinación interinstitucional, de modo nadie se hace responsable de lo que está ocurriendo a lo largo del proceso, y menos aún de los sentimientos del sujeto infantil y de sus familiares, ni tampoco de los problemas que atraviesan a consecuencia de la intervención.

Cabe añadir que, a pesar de ser un fenómeno muy conocido, escasean investigaciones sobre el disfuncionamiento institucional y sus repercusiones en el psiquismo del menor. El presente estudio pretende visibilizar aquellas dificultades encontradas en el proceso que sigue la denuncia de abusos sexuales, por el niño y los que le acompañan en el largo recorrido a través de las instituciones encargadas de la protección de la infancia.

\section{Víctimas y revictimización}

Interrogar la revictimización, lleva a preguntarnos cuál es el sentido dado a la palabra "víctima", y más específicamente "víctima de abuso sexual", sobre todo cuando se tratan de menores de edad. En efecto, el problema de las vícti- 
mas desborda y a la vez encubre el tema que se quiere analizar aquí, el de los niños y adolescentes que han sufrido alguna situación de violencia y que -en el curso del proceso de atención o como su consecuencia- viven algún nuevo tipo de agresión.

La cuestión de las víctimas ha sido abordada desde múltiples perspectivas, hasta el punto que la nueva justicia restaurativa que se quiere implementar en muchos países, considera que las víctimas constituyen el eje central en su propuesta de reelaboración. Empero en el mundo de hoy, víctima es una palabra cuyo uso se ha extendido mucho, hasta el punto que parece difícil no ser víctima de algo. Es importante no caer en esta distorsión del concepto que le resta valor operativo y rigor.

En su sentido etimológico, ser víctima significa "ser el objeto de un sacrificio", o sea es víctima quien se transforma en mero objeto a mano de otros que lo utilizan para su propia satisfacción. De modo que cuando uno está colocado en el lugar de víctima, está privado de su esencia de persona única, de su subjetividad, tan importante para sostener su deseo singular y permitirle sobrevivir en un mundo cada día más áspero.

A continuación, usaremos la palabra "víctima" para hablar de los niños, niñas y adolescentes que han sufrido algún abuso sexual, o sea una agresión en su sexualidad y que, en razón de su edad y condición, han sido afectados en su integridad física y/o psíquica (Dupret, 2012), y por ende en su construcción subjetiva. Sin embargo, dejaremos de lado conductas de promiscuidad de adultos con niños, conductas no conformes a las normas de comportamiento admitidas por su sociocultura, como juegos sexuales inapropiados, pero sin consecuencias graves y duraderas en la psique infantil.

La significación de "revictimización" puede ahora precisarse como reiteración de una victimización, según lo indica la palabra, y que apunta a la reproducción de una situación de victimización anterior. La revictimización es, por tanto, una repetición de violencias contra quién ha sido previamente víctima de alguna agresión, aunque sea por omisión. Sin embargo, la palabra ha adquirido un sentido algo diferente, que sirve para referirse en especial a las vivencias de maltrato sufridas por los niños y sus familiares, en el curso de intervenciones institucionales después de la denuncia de un abuso sexual u otra violencia, y 
remite por lo tanto a una falencia en el abordaje y tratamiento de la situación de violencia.

Más específicamente, se entiende por revictimización institucional, a las carencias ligadas a la atención recibida por parte de entes dedicados a la protección de la niñez y adolescencia. La más conocida se manifiesta en la dificultad de articulación y remisión entre las distintas instituciones a cargo del bienestar y de la protección de los menores, lo que lleva al "peloteo", o sea el paso de una institución a otra, sin que ninguna se haga cargo; cada una considerando que no es de su competencia, de modo que al fin nadie se responsabiliza por el caso y no existe ningún tipo de seguimiento del proceso. Otro aspecto muy típico y que deriva del primero, es la multiplicación de entrevistas, exámenes periciales, interrogatorios, y pruebas de toda índole, muy a menudo con una falta de profesionalidad de los intervinientes.

En fin, lo más característico de la revictimización, es el trato recibido por el menor, considerado más como cosa desechable, que como sujeto que sufre a raíz del daño experimentado, causa de la denuncia. En esta aceptación resurge el sentido original de la palabra "víctima" como mero objeto del sacrificio, en el cual su subjetividad pierde valor y la singularidad de su ser desaparece.

Aunque hablemos de niños, niñas y adolescentes, aquí dejaremos de lado el tema de los menores infractores, porque su revictimización en el seno de los centros de orientación, requiere un abordaje muy específico y un análisis detallado de su situación. Para entender mejor la realidad del fenómeno, presentaremos cuatro casos de menores que ejemplifican situaciones de "revictimización", debido a las distorsiones de la atención institucional que han experimentado y el descuido por su sufrimiento en el curso de la denuncia.

\section{Recorrido de revictimización e intervenciones institucionales}

A continuación describiremos y analizaremos cuatro casos de delitos sexuales referidos a la Oficina de Atención a la Ciudadanía del Ministerio de Justicia, Derechos Humanos y Cultos durante los años 2009 y 2010, los cuales han atravesado meses, incluso años, por un proceso administrativo de justicia en que los menores y sus familiares han sido revictimizados de distintas maneras. 


\section{Caso de Esteban ${ }^{3}$}

El caso es dado a conocer al Ministerio de Justicia por parte de la madre de la víctima, quien manifiesta que su hijo de 3 años de edad fue abusado sexualmente por el padre del niño y su conviviente. El abuso incluye, presuntamente: exposición de Esteban a la desnudez propia y de la pareja; besos en la boca; manipulación de las partes íntimas del pequeño; producción de material audiovisual de las escenas y posiblemente violación, inferida de lesiones del niño en la zona anal.

\section{Caso de Marina}

El caso es dado a conocer al Ministerio de Justicia por un organismo de defensa derechos, que realiza la veeduría de un caso de atentado contra el pudor. Marina, tras el fallecimiento de su madre, es entregada en custodia a su padre sin tomar en cuenta antecedentes denunciados de violencia intrafamiliar ni que la niña había convivido siempre con sus abuelos maternos. El padre lleva a Marina a vivir en el exterior; tras una visita al país, ella revela que su padre la maltrataba físicamente y le exponía ante situaciones consideradas penalmente como abuso, incluida la manipulación de sus partes íntimas.

\section{Caso de Lucía}

El caso es dado a conocer al Ministerio de Justicia por la Presidencia de la República. Se trata de una niña de 13 años de edad que ha sido abusada sexualmente por su tío durante un lapso de 3 años.

3 Los nombres y algunos detalles han sido modificados para preservar el anonimato de los casos. 


\section{Caso de Sara}

El caso es puesto en conocimiento del Ministerio de Justicia por la madre de la víctima. La señora manifiesta que Sara fue violada en dos ocasiones por el inspector del colegio donde estudia la adolescente; la primera vez, cuando la adolescente tenía 14 años y la segunda, a los 15 años. Para el efecto, en la segunda ocasión, el presunto victimario, se valió de amenazas para obligar a Sara a encontrarse en un determinado lugar y abusar de ella.

\section{Las instituciones que conocieron los casos}

\section{Caso de Esteban}

Fiscalía Provincial, DINAPEN, INNFA, Fiscalía Provincial (de una segunda provincia), Programa de Protección a Víctimas, Consejo Nacional de la Niñez y Adolescencia, Hospital de Niños Baca Ortiz, Organización de Defensa de Derechos de Mujeres, Presidencia de la República, Ministerio de Justicia, Derechos Humanos y Cultos.

\section{Caso de Marina}

Comisaría Segunda de la Mujer y la Familia, Fiscalía Provincial, Organización de Defensa de Derechos de Mujeres, Juzgado Primero de la Niñez y la Adolescencia, Juzgado Sexto de la Niñez y Adolescencia, Tribunal Cuarto de Garantías Penales, Corte Nacional de Justicia, Consejo Nacional de la Niñez y Adolescencia Organización de defensa de derechos de personas en movilidad, Presidencia de la República, Corte Constitucional, Ministerio de Justicia, Derechos Humanos y Cultos. 
Caso de Lucía

Fiscalía Provincial, Corte Provincial, MIES, INNFA (de dos provincias), Ministerio de Justicia, Derechos Humanos y Cultos.

\section{Caso de Sara}

Fiscalía Local, Fiscalía Provincial, Juzgado Octavo de Garantías Penales, Corte Provincial de Justicia, Defensoría del Pueblo, Organización de defensa de derechos, Ministerio de Justicia, Derechos Humanos y Cultos.

\section{Entrevistas realizadas}

\section{Caso de Esteban}

Delito: violación

Se realizan al niño dos exámenes médicos legales proctológicos. En el primer examen consta en el expediente que "por ocasiones y con ayuda del equipo técnico se intenta realizar el examen físico pero el menor no permite el desarrollo del mismo".

Entrevistas y terapias: Fiscalía Provincial, INNFA, Programa de Protección a Víctimas y Testigos, INNFA (de otra provincia), Hospital de Niños Baca Ortiz.

\section{Caso de Marina}

Delito: Atentado contra el pudor

La Comisaría de la Mujer y la Familia ordena se realice una entrevista y evaluación psicológica en el CEPSS. La Fiscalía dispone se recepte la versión de la víctima ante la fiscal. La Fiscalía dispone se realice el examen psicológico a la niña. 
Caso de Lucía

Delito: atentado al pudor

Exámenes psicológicos: Fiscalía Provincial e INNFA

Caso de Sara

Delito: violación

Testimonio de la víctima ante el fiscal en presencia del agresor y de su abogado. Examen médico legal. Examen psicológico en la Fiscalía. Nueva entrevista en el INFFA para recibir apoyo psicológico.

\section{Resolución de los casos y análisis de las diferentes situaciones de revictimización}

Para entender mejor el problema de la revictimización, se agrupará los diferentes tipos de instituciones encargadas de protección, involucradas en cada caso tras la denuncia o develación del hecho.

1. Instituciones operadoras de justicia

2. Instituciones administrativas de protección de derechos

3. Instituciones estatales que realizan la veeduría del debido proceso

4. Instituciones estatales de atención

5. Instituciones no gubernamentales de atención, promoción y protección de derechos 


\section{Instituciones operadoras de justicia: fiscalías provinciales y locales}

\section{Caso de Esteban}

Actuación: Recepción de la denuncia e impulso de la investigación, en colaboración entre dos Fiscalías provinciales, debido al cambio de domicilio de la víctima. Peritaje psicológico realizado al niño. Peritajes médico proctológico, a los que el niño opone resistencia ansiosa. Incorporación de la víctima y su madre al Programa de Protección de Víctimas y Testigos (PPTV).

Evolución del Proceso: El peritaje psicológico concluye que hay indicadores de abuso sexual. Tras el segundo examen, se evidencia que existe una lesión antigua en la zona anal, producto de un objeto penetrante. El PPTV coordina para que el niño y la madre cuenten con vivienda, además de atención psicológica, médica y educación para el niño. Tiene lugar una entrevista psicológica al niño en el PPTV, tras lo cual se concluye que necesita iniciar un proceso psicoterapéutico de manera urgente.

Problemas durante el proceso: La madre de Esteban desconfía de las actuaciones de Fiscalía. Por ello y debido a la escasez de recursos económicos, impulsa ella misma la causa, pero con pocos conocimientos en derecho a su haber. El niño y su madre se cambian constantemente de domicilio (en la nueva ciudad), debido a presuntos problemas ocasionados por la madre. La madre también desconfía del PPTV, y este a su vez desconfía de que la madre proporcione al niño un buen trato.

Resultados: Archivo de la causa por parte de Fiscalía, con el argumento de que, pese a los resultados de los peritajes, no existirían elementos suficientes para probar la responsabilidad del demandado. $\mathrm{Al}$ archivarse la causa, la madre y el niño salen del PPTV. Debido al grado de involucramiento de la madre en el impulso de la causa, ella no pudo encontrar un trabajo estable mientras contó con la protección del Programa, por lo que al salir de este quedó en una situación económica complicada. 


\section{Caso de Marina}

Actuación: Recepción de la denuncia e impulso de la investigación. Recepción de la versión de la víctima. Peritaje psicológico, del que se obtiene la filmación de dos sesiones.

Evolución del proceso: En la toma de versiones, Marina expone los hechos denunciados y otros que involucran más al acusado. Se deriva que la niña se mantiene en el relato de los hechos develados y que presenta síntomas de estrés postraumático y rechazo hacia el padre.

Problemas durante el proceso: El peritaje psicológico tomado por Fiscalía es el segundo proceso de evaluación psicológica a la niña es sometida.

Resultados: La Fiscalía dicta instrucción fiscal para llevar el caso a juicio.

\section{Caso de Lucía}

Actuación: Recepción de la denuncia e impulso de la investigación. Se realiza un peritaje psicológico a la niña.

Evolución del proceso: Del peritaje psicológico se deriva que sí, hubo abuso sexual, sostenido por largo tiempo. Además pone de relieve los efectos psíquicos y psicosomáticos que el abuso ha producido en la víctima.

Resultados: Se dicta instrucción fiscal.

\section{Caso de Sara}

Actuación: La Fiscalía en que es puesta la denuncia se abstiene de conocer el caso por estar fuera de su jurisdicción y envía a la denunciante a la jurisdicción correcta. Ahí se recepta la denuncia y se impulsa la investigación.

Resultado: La Fiscalía dicta instrucción fiscal.

Análisis de las intervenciones de las fiscalías provinciales y locales: En todos los casos mencionados, la Fiscalía, de acuerdo con sus competencias, recepta la denuncia e impulsa la investigación del caso. En estos casos, se dicta instrucción fiscal cuando se tienen elementos suficientes que evidencien que 
sí hubo un posible delito y que se identifican a los responsables. Sin embargo, llaman la atención los dos casos en los que la instrucción fiscal no se dictó. En efecto, pese a que los peritajes realizados concluyen que: "los cambios de comportamiento que presenta el niño, los trastornos del sueño, la enuresis y la manipulación compulsiva de sus genitales, son indicadores habituales del abuso sexual que se investiga", (entrevista psicológica); "la región anal presenta una laceración antigua localizada como a las doce si comparamos a esta región con la esfera del reloj, producto de la acción penetrante de un objeto vulnerante por esa vía" (examen médico legal proctológico); "el niño ha sido víctima de un delito de carácter sexual y necesita iniciar un proceso psicoterapéutico de manera urgente" (entrevista psicológica Unidad de Protección a Víctimas) se archiva la causa. Este caso es paradigmático, porque un elemento que atraviesa la historia desde el principio, es la desconfianza de la madre de Esteban en la actuación de la Fiscalía y en la protección que pueda brindarle el PPTV; la desconfianza es recíproca por parte del PPTV, en cuanto al trato para su hijo. La mutua desconfianza víctima-institución es generada por y a su vez genera una serie de obstáculos jurídicos y logísticos en el proceso de investigación. Todo esto lleva a la madre del niño a asumir una participación activa en el impulso del proceso y a acudir desesperadamente a todas las instituciones que pueda para respaldarse y que el delito no quede en la impunidad. Estos "obstáculos", vistos así por el PPTV, generados por la denunciante, dan cuenta de las dificultades de esta institución para brindar una adecuada contención a las víctimas directas e indirectas. Adicionalmente, es importante destacar la duplicación de peritajes. En el caso de Esteban, la madre de la víctima solicita que se repita el examen médico legal al niño abusado, pues la falta de contención a la angustia del niño cuando el médico quiso revisar sus zonas íntimas, incidió en que el examen no pueda realizarse a cabalidad; en el segundo examen (realizado a destiempo) también se presentan resistencias del niño, aunque ya es posible llevarlo a cabo.

En el caso de Marina, la Fiscalía no puede hacer válida la primera evaluación psicológica que se realiza a la víctima, debido a que el procedimiento al que debe atenerse no se lo permite, porque fue solicitado desde una Comisaría a un Centro privado. Esta decisión se da a pesar de que el Código de la Niñez y Adolescencia en la parte referente los exámenes médico legales en su Art. 80 señala: "Los informes de dichos exámenes, realizados por profesionales de 
establecimientos de salud públicos o privados y entidades de atención especializadas, tendrán valor legal de informe pericial".

\section{Instituciones operadoras de justicia: juzgados de la niñez y adolescencia y juzgados de garantías penales}

\section{Caso de Marina}

Actuación: Un Juzgado de la Niñez y la Adolescencia conoce una demanda del presunto victimario para la restitución de la niña. Otro Juzgado de la Niñez y Adolescencia conoce una demanda presentada por la abuela de la niña para la privación de tenencia en contra del acusado. El caso llega hasta un Tribunal de Garantías Penales. La abuela de la niña solicita un recurso de casación ante la Corte Nacional de Justicia.

Resultados: En el primer Juzgado el Juez ordena que la abuela entregue de forma inmediata la niña a su padre. En el otro Juzgado donde la abuela presenta la demanda, se inicia el proceso. En el Tribunal de Garantías Penales se dicta sentencia absolutoria en favor del victimario. La Corte Nacional de Justicia declara al recurso de casación improcedente.

\section{Caso de Lucía}

Actuación: Se realiza el juicio en contra del demandado. La parte demandante interpone un recurso de apelación ante la Corte Provincial de Justicia. La ofendida interpone una acción extraordinaria de protección ante la Corte Constitucional.

Resultados: En el juicio, el juez falla a favor del demandado. La Corte Provincial de Justicia sobreseyó temporalmente al acusado. La Corte Constitucional todavía no emite una resolución. 


\section{Caso de Sara}

Actuación: El Juzgado de Garantías Penales toma el testimonio de las víctimas y ordena la realización de peritajes médico y psicológico.Un familiar de la víctima interpone un recurso de apelación ante la Corte Provincial de Justicia.

Evolución del proceso: De los peritajes médico y psicológico concluyen que sí hubo violación. El juez dicta prisión preventiva en contra del acusado, pero esta no se ejecuta.

Problemas durante el proceso: La defensa contra-acusa a la víctima de realizar pornografía por internet.

Resultados: Se da un dictamen acusatorio pero el acusado huye. El recurso de apelación sigue en trámite.

Análisis: En lo que se refiere a los juzgados, llama la atención cómo en un caso, se anula la prisión preventiva dictada por el Juez sin que se dé a conocer los argumentos para tal decisión. En el único juicio en que existe un dictamen acusatorio (caso de Sara), el acusado huye y la prisión preventiva no se hace efectiva. En los otros dos juicios (casos de Marina y Lucía), la sentencia es a favor del demandado, a pesar de que los peritajes psicológicos -en los que el testimonio de la víctima ocupan un lugar central- son muy claros respecto a que los síntomas de las niñas, evidencian que ellas han sufrido una situación de abuso sexual.

Esto nos da una pista sobre el valor que tiene el testimonio del niño e incluso los informes periciales en el campo psicológico, dentro del proceso judicial de nuestro sistema. Al estar todo testimonio atravesado inevitablemente por la subjetividad de quien lo rinde (y sumado a esto todos los prejuicios respecto del testimonio del niño), los abogados de la defensa y el mismo tribunal podrían calificar como "falta de objetividad" si se lo tomara como único argumento para una sentencia condenatoria.

Como vimos previamente, la carencia de sanciones efectivas en contra de quien abusó sexualmente de un niño, produce en él la sensación de que no valió la pena haber develado la situación de la que eran víctimas y que, por el contrario, quedaron sobre expuestos a la mirada de un sinnúmero de personas desconocidas que lo examinaron e interrogaron para comprobar si estaba diciendo "la verdad". El niño abusado cuya palabra no está tomada en cuenta por la justi- 
cia, encuentra mayores dificultades para soportar y tramitar los sentimientos de confusión, culpa, vergüenza y sufrimiento que la situación de ultraje de su intimidad le ha provocado. Se analizará este aspecto más adelante en el párrafo 3.3.

\section{Instituciones administrativas de protección de derechos: comi- sarías de la mujer y la familia y juntas cantonales de protección de derechos}

\section{Caso de Marina}

Actuación: La Comisaría de la Mujer y la Familia, que conoce la denuncia de abuso sexual, dispone se realice la Investigación Social y Psicológica a la víctima.

Evolución del proceso: La evaluación psicológica concluye que existen signos evidentes de que la niña ha sido víctima de atentado al pudor por parte de su padre.

Resultados: La Comisaría concede a la abuela medidas de amparo (boleta de auxilio).

Análisis: Este caso llegó a una instancia Administrativa de Protección de Derechos. Mucho se ha discutido en el país sobre las dificultades que se generan cuando instituciones de tipo administrativo actúan en casos de violencia que revisten el carácter de delito. Aquí, nos encontramos con un claro ejemplo de ello: en el caso Marina, se produce una duplicidad de peritajes psicológicos, debido a que la Comisaría de la Mujer dispone que se realice un examen a la niña, a sabiendas de que los resultados de dicho examen no podrán ser utilizados posteriormente por la Fiscalía. Esta duplicación de esfuerzos no solo evidencia una falla en la eficiencia de un sistema de protección que pretende ser "integral" - en el sentido en que sus instituciones deberían actuar coordinadamente-, sino que de hecho deja traslucir cómo, lejos de proteger, un sistema así desarticulado, al multiplicar los exámenes, desprotege y revictimiza gravemente al menor. 


\section{Instituciones estatales de veeduría al debido proceso: Consejo Nacional de la Niñez y Adolescencia}

\section{Caso de Esteban}

Actuación: El Consejo Nacional de la Niñez y Adolescencia, al conocer el caso, asume la vigilancia.

Evolución del proceso: El Consejo Nacional de la Niñez y Adolescencia remite comunicaciones a la Fiscalía, solicitando se respete el derecho al debido proceso.

Resultados: No obtuvieron respuesta.

\section{Caso de Marina}

Actuación: La abuela de la niña acude al Consejo Nacional de la Niñez y Adolescencia, quien asume la vigilancia del proceso.

Evolución del proceso: El Consejo Nacional de la Niñez y Adolescencia remite comunicación al Ministerio de Justicia.

\section{Caso de Lucía}

Actuación: La Defensoría del Pueblo asume la veeduría.

Análisis: Por un lado, es llamativo el que en tres de los cuatro casos, se haya considerado la opción de contar con el apoyo de una instancia estatal que realice una veeduría al debido proceso. Un requerimiento de este tipo se produce cuando existen sospechas de irregularidades que atenten en contra del derecho a un proceso justo.

Por otro lado, también es destacable cómo en estos casos la participación tanto del Consejo Nacional de la Niñez y Adolescencia como de los Concejos Cantonales, sea también en calidad de veedores del debido proceso, en paralelo -para todos los casos- e incluso en coordinación con la actuación de la Defensoría del Pueblo. ¿Se trata, acaso, de una duplicación de esfuerzos que dé 
cuenta, nuevamente, de la falta de eficiencia del sistema integral de protección? $\mathrm{O}$, por el contrario, ¿nos muestra este dato que existe poca credibilidad, incluso entre las diferentes instancias del mismo Estado, respecto de una adecuada administración de justicia en materia de niñez y adolescencia? Esta última pregunta nos lleva, inevitablemente, a otra de carácter más político: ¿Por qué tiene el Estado la necesidad de auto-vigilarse doblemente cuando se trata de proteger los derechos de menores víctimas de abusos sexuales?

\section{Instituciones estatales de atención: DINAPEN, INNFA, Centro de Protección de Derechos del MIES}

\section{Caso de Esteban}

Actuación: La DINAPEN recepta la denuncia realizada por la madre del niño por su secuestro. El INNFA realiza entrevista y terapia psicológica. También brinda apoyo en el área legal. El Ministerio de Justicia brinda asesoramiento interdisciplinario a la madre de Esteban y coordina acciones con otras instituciones. En un Centro de Protección de Derechos del MIES-INNFA, la psicóloga mantiene una entrevista con la madre y el niño que, luego, acude a terapias. Por recomendación de la perito psicóloga de Fiscalía Provincial, la madre acude al Hospital de Niños Baca Ortiz para que Esteban reciba terapia psicológica. La madre pone en conocimiento el caso en la Presidencia de la República.

Evolución del proceso: El presunto victimario fue acusado de ser el secuestrador. La madre es enfática en sus sospechas sobre irregularidades en el proceso presentadas en la Fiscalía de la localidad en que el delito fue cometido y solicita asesoramiento para llevar el caso en la ciudad de Quito. Se pone la situación en conocimiento del Consejo Nacional de Niñez y Adolescencia; se mantiene una reunión interinstitucional con el PPVT, CNNA, INNFA y una organización de defensa de derechos de la mujer para coordinar el seguimiento inter-institucional del caso; y se solicita a la Defensoría Pública Penal que asuma su patrocinio. La psicóloga de la Fiscalía sugiere la terapia del niño en el hospital, a sabiendas (según lo refiere la madre) de que Esteban ya asistía 
a terapia en el INNFA; aparentemente esta profesional sostenía que no había problema en que el niño trabaje con dos psicólogas a la vez.

Problemas durante el proceso: Se evidencia que la madre del niño había acudido a casi todas estas instituciones para solicitar apoyo profesional jurídico, psicológico y social.

Resultados: El mismo día de la denuncia, la DINAPEN recupera al niño. El caso no se traslada de jurisdicción por imposibilidades procedimentales, pero sí existe coordinación entre Fiscalías provinciales. El Consejo Nacional de la Niñez envía una comunicación que remitieron a la Fiscalía, en la cual indican las irregularidades presentadas en el caso y solicitan se respete el derecho al debido proceso. Por iniciativa del Ministerio de Justicia, diferentes instituciones firman una comunicación conjunta dirigida a la Fiscalía, solicitando se considere no archivar la causa. La Defensoría Pública Penal, en varias ocasiones, se niega a asumir el patrocinio, argumentando que el caso estaba ya muy avanzado y que se habían producido muchos obstáculos de tipo jurídico por desconocimiento desde la parte acusatoria (es decir, desde la madre misma del niño). La Presidencia solicita al Ministerio de Justicia informes sobre el caso.

\section{Caso de Marina}

Actuación: La Presidencia de la República recibe una comunicación de una organización de defensa de derechos. El Ministerio de Justicia solicita a la Defensoría Pública Penal que patrocine el caso.

Resultados: La Presidencia de la República remite dicha comunicación al Ministerio de Justicia; un abogado de la Defensoría Pública patrocina el caso.

\section{Caso de Lucía}

Actuación: Los Centros de Protección de Derechos del MIES INNFA de dos localidades conocen el caso. El Ministerio de Justicia sugiere continuar impulsando la causa (acción extraordinaria de protección) y remite a la Defensoría del Pueblo para que realice una veeduría. 
Resultados: El Centro de Protección de Derechos asume el patrocinio del caso y la Defensoría del Pueblo inicia la veeduría.

\section{Caso de Sara}

Actuación: El Ministerio de Justicia sugiere acudir a los Consultorios Jurídicos Gratuitos de la PUCE para que sigan el proceso de sustanciación de la causa. Además se contacta con un Centro de Protección de Derechos para que la adolescente reciba atención psicológica.

Resultado: Las personas involucradas en el caso reciben atención de las instituciones a las que fueron remitidas.

Análisis: Se ha agrupado, en esta categoría, a varias instituciones estatales del poder ejecutivo que, a pesar de que, como en el caso de los ministerios, no se centran en la atención directa, se han articulado en estos casos en concreto como instancias que mantienen un contacto directo con las víctimas y brindan una atención especializada, dentro del ámbito de sus competencias institucionales.

En la intervención de estas instituciones, ${ }^{4}$ se puede notar algunos esfuerzos de coordinación interinstitucional, si bien en algunos casos (por ejemplo, en el caso de Esteban), esta no se realiza desde el inicio, sino que aparece como una necesidad en un momento ya avanzado del seguimiento. Aunque en teoría, todas las Instituciones Estatales son partes del sistema integral de protección -y esto les obliga a un trabajo articulado y en red-, en la práctica no existe una estructura que delimite cómo se producirá dicha intervención. Es decir, el trabajo articulado en estos casos ha dependido, más que de un procedimiento claro, de la voluntad y el compromiso de las personas que, en cada institución, asumieron la responsabilidad de seguir los casos.

La falta de claridad respecto de los ámbitos de intervención y de estructura de coordinación de los casos, ha incidido en una falta de contención institucional a las víctimas, quienes se han visto obligadas a "tocar todas las puertas" que han tenido a disposición, para asegurarse de alguna manera, algo de apoyo

4 Con excepción de la DINAPEN, que entra en escena en un momento en concreto de un solo caso. 
institucional en medio de la sensación de desprotección judicial. Pero, aunque hayan encontrado en cada institución una atención, intervención y/o respuesta más o menos adecuada y más o menos esclarecedora a su situación, también ha resultado que muchas veces obtuvieron orientaciones profesionales con criterios muy diversos e incluso contradictorios, que ahondaron su sensación de desamparo e incidieron en el proceso de revictimización. Un claro ejemplo de ello es el caso de Esteban, en que su madre recibe por parte de una psicóloga de la Fiscalía el consejo de que lleve a su hijo "a dos terapias", opción que ella acepta, a pesar del criterio de las psicólogas del INNFA y del Ministerio de Justicia de que esto puede ser perjudicial para el niño.

\section{Instituciones no gubernamentales de atención, promoción y protección de derechos: Organización de Defensa de Derechos de Mujeres, Organización de Derechos Humanos}

\section{Caso de Esteban}

Actuación: La Organización de Defensa de Derechos de Mujeres asiste a reunión interinstitucional en el Ministerio de Justicia, para coordinar acciones de seguimiento.

Resultado: La organización de defensa de derechos de mujeres es parte de las instituciones que conjuntamente firman una comunicación dirigida a la Fiscalía para solicitar que se considere no archivar la causa.

\section{Caso de Marina}

Actuación: Una organización de los Derechos de las Mujeres asume una veeduría ciudadana del proceso. Otra organización de Defensa de Derechos de Personas en situación de Movilidad conoce el caso por iniciativa de la abuela.

Resultados: La organización de los Derechos de las Mujeres, como parte de las acciones de veeduría, pone el caso en conocimiento del Ministerio de Justicia. La organización de Defensa de Derechos de Personas en situación de 
Movilidad, remite una comunicación a la Presidencia de la República dando a conocer el caso.

\section{Caso de Sara}

Actuación: La Organización de Derechos Humanos asume una veeduría ciudadana del proceso. Una fundación de Defensa de Niñas, Niños y Adolescentes, además de sumarse a la veeduría ciudadana, realizan en conjunto una entrevista con las víctimas a fin de evaluar la gravedad del caso y planificar acciones para la restitución de los derechos conculcados.

Resultados: Las organizaciones de Defensa de Derechos Humanos y de Defensa de Niños, Niñas y Adolescentes, ponen en aviso del delito ocurrido a las autoridades pertinentes (Juntas de Protección de Derechos y Fiscalía), así como a otras instituciones estatales, entre ellas al Ministerio de Justicia.

Análisis: Por último tenemos a las instituciones no gubernamentales de atención. Muchas veces son estas las primeras instituciones en conocer un caso de abuso sexual infantil, y la intervención que asuman o no, posibilita -y también exige- la acción del Estado como garante principal de la protección de la niñez y de la adolescencia.

En los tres de los cuatro casos analizados, vemos cómo estas instituciones no se han conformado solo con poner en conocimiento del Estado el delito ocurrido, sino que presionan y, de ser posible y necesario, trabajan "codo a codo" con las instituciones estatales de veeduría y de atención directa, para presionar a su vez al sistema judicial a que respete el debido proceso y no deje a los casos en la impunidad. Este trabajo de apuntalamiento de la acción de las instituciones estatales, es positiva en el sentido de que da cuenta de un nivel de participación efectivo de la sociedad civil en el sistema de protección integral; pero también pone en evidencia, nuevamente, que la articulación del sistema integral de protección a nivel estatal, es todavía tan débil, que requiere "refuerzos" de la sociedad civil, ${ }^{5}$ para dar mayor peso y consistencia a las intervenciones.

5 Nótese esto en el hecho de, por ejemplo, dirigir cartas a las distintas instancias de administración de justicia, firmadas en conjunto por instituciones estatales y no gubernamentales. 


\section{Efectos y consecuencias de la revictimización institucional en el psiquismo del niño}

La revictimización, mucho más que un paso desagradable en el curso de una intervención psicosocial y jurídica después de la denuncia de casos de abuso sexual, es una forma de agresión muy perniciosa, porque impregna de su sello todas las dimensiones constitutivas del sujeto humano, en particular cuando es muy joven y dependiente de su relación con los adultos. La revictimización surge:

Cuando en lo real, el niño se topa con el muro de indiferencia y mutismo de las instituciones.

Cuando experimenta, en lo imaginario de su sensibilidad infantil o adolescente, sensaciones de miedo, emociones sin explicación, percepciones de un mundo adulto donde no tiene ningún lugar.

Cuando, en medio de su desamparo, encuentra silencio e desinterés, en lugar de palabras simbolizantes.

\section{Circunstancias y hechos de la revictimización}

Como lo ilustran los cuatro ejemplos descritos anteriormente, después de la denuncia de un abuso sexual, la forma más inmediata de revictimización, y sin duda la más visible, es el paso del menor por múltiples instituciones anónimas, donde se enfrenta al desentendimiento manifestado por algunas de ellas, así como por las personas que las encarnan. Por distintas razones que no se profundizarán aquí, muchas de ellas, a pesar de estar encargadas de vigilar por el bienestar superior del niño y por ende por su protección, prefieren no inmiscuirse en problemáticas de violencias, sobre todo cuando se tratan de cuestiones intrafamiliares. ${ }^{6}$ De modo que optan por remitir los casos a otra institución que, a su vez, se lava las manos y dirige el caso hacia otra, la misma que a veces vuelve a mandar al niño a una por la cual pasó anteriormente. Lo más llamativo

6 Es más fácil dar un golpe de fuerza en una escuela, sin mayores consecuencias, que entrar en la dinámica mortífera de una familia con la cual luego no se sabe cómo proceder. 
de esta situación, es la desgana evidente de estas instituciones por asumir la responsabilidad y el seguimiento de los casos, tal vez debido sobre todo a su sentimiento de incapacidad para intervenir de manera adecuada.

Dentro del recorrido institucional, otra causa de revictimización, esta vez cuando por fin hay atención, es la multiplicación de entrevistas, de tests, exámenes periciales, interrogatorios y otras pruebas, que se repiten sin que nadie se encargue de centralizar y coordinar el tipo de atención que se brinda al menor ni tampoco la información obtenida; de modo que el niño a menudo se sienta acosado por tantas preguntas, y opte por no responder más, lo que no raras veces conduce a considerarle como un mentiroso. ${ }^{7}$ A este desánimo y cansancio del niño, cabe añadir el desgaste psicológico de los acompañantes, frente a la indiferencia y a las torpezas de las instituciones. ${ }^{8}$

Al lado de esta falta de atención, otro elemento que marca mucho la afectividad infantil, aunque no suele tomárselo en cuenta en el trascurso del proceso psicosocial y jurídico, es la vivencia dentro de la familia. En efecto, ocurre muy a menudo que a lo largo del lento camino de la denuncia del abuso sexual, la homeostasis del grupo se vea perturbada y que la fratría, e incluso la madre o el padre, manifiesten sentimientos de hostilidad en contra del niño por haber causado un revuelo en su seno (Haesevoets, 2003).

Por fin, no hay que olvidar que la ausencia de respuestas institucionales y la interrupción de los procesos, pueden conducir al reenvío del niño a las manos de su victimario; una situación lamentable con consecuencias devastadoras que deja presagiar un porvenir muy triste para quien haya sido agredido en lo más íntimo de su alma, cuando el dolor de la agresión queda encerrado en el silencio de la incomprensión y del sinsentido; cuando se grabe la impresión de un destino ineludible, en un ser todavía en relación de sumisión física y afectiva con los adultos de su entorno (Barudy, 1998).

7 Sobre el sentido de la mentira para un niño véase Piaget (1960).

8 El protocolo de la "entrevista única" (2000) está concebido para evitar la repetición de exámenes periciales inútiles. (Véase Coulborn Faller, 1993). 


\section{La ignorancia de la sensibilidad infantil, una causa de revictimiza- ción ${ }^{9}$}

La descripción de los cuatro ejemplos se centró en los aspectos formales de las intervenciones institucionales sin entrar en un análisis cualitativo. Sin embargo, es fácil deducir de las carencias de los procesos que una de las principales causas de revictimización, es el desconocimiento de las características del psiquismo infantil por parte de los intervinientes, muy en especial la falta de una preparación especializada de los profesionales de la función judicial y, por ende, la inexistencia de un asesoramiento psicológico en las intervenciones que involucran a menores

El imaginario infantil es muy diferente del adulto; experimenta las situaciones en las cuales está involucrado a partir de su nivel de desarrollo psíquico en el cual predominan sensaciones y emociones que no pueden verbalizarse fácilmente. El miedo al adulto por lo ocurrido durante el abuso y/o por las amenazas de castigo, puede entorpecer cualquier forma de expresión, que sea oral o a través de dibujos, de modo que los interrogatorios y pruebas a los cuales está sometido, pueden resultar completamente falsificados y dar la impresión que no pasó nada, el típico punto de vista del profesional que no haya sido capacitado para tratar a un niño.

Además, el adulto, por su manera de dirigirse al menor, puede asustarle y no crear un lazo de empatía, es decir una relación de transferencia, a pesar de su importancia para interpretar sus actuaciones y respuestas. Este desconocimiento de la sensibilidad infantil, puede llevar al profesional a utilizar un discurso crudo para referirse a las violencias experimentadas, unas palabras que no preserven el imaginario del niño, fomentando un nuevo trauma envuelto de pesadillas y angustias.

Por este motivo, en algunos países como Canada o Francia, se recomienda que un especialista de la infancia, siempre acompañe al menor en todas las etapas de la investigación de la denuncia y del proceso, y sirva de mediador entre

9 Los niños tienen una visión del mundo y un uso de la palabra muy diferentes del de los adultos, lo que indica la necesidad de una preparación especial para relacionarse con ellos. 
él y el profesional a cargo de estudiar cada aspecto específico de los hechos ocurridos (médico, abogado, policía).

\section{Desconsideración hacia la palabra del niño y revictimización}

A raíz de la denuncia de un abuso sexual, las dos formas de revictimización antes mencionadas, debidas al tipo de respuesta - o no respuesta- a la demanda de atención, y al desconocimiento del pensar y actuar propio a un menor, desembocan a menudo en una tercera forma de revictimización, esta vez en el plan simbólico, cuando la palabra del niño no está escuchada, o cuando el profesional considera que no vale la pena tratar al niño como ser pensante, ni dirigirse a él como a una persona que entiende lo que ocurre. En efecto, en las prácticas institucionales, muy a menudo, la víctima infantil está considerada como mero objeto de la intervención, sin que se dé mayor atención a su subjetividad de ser dotado de palabra (Ferenczi, 1933).

A este nivel, podemos distinguir diferentes aspectos. Muy a menudo, los profesionales no toman el tiempo de explicar al menor lo que está sucediendo, la razón de ser de tal examen o lo que significa el paso por tal otra instancia, de modo que el niño puede experimentar una suerte de despersonalización en el curso de intervenciones cuyos objetivos no entiende. No cabe duda que la peor forma de revictimización a este nivel, es la falta de respeto a la palabra del niño y a su manera de expresar lo vivido. Paradójicamente, sucede a veces que esté tratado como una cosa inanimada, y aunque se anote lo que él dice, no se toma en serio sus palabras como la expresión de un testigo privilegiado, aunque diferente de un adulto, sino como espectador anónimo, invitado de piedra insensible a lo que le ha pasado.

Este hecho es particularmente llamativo en las entrevistas y los cuestionamientos de los abogados que buscan una verdad a su medida, y no la verdad experimentada por el niño. De ahí, el desprecio al menor y la tendencia muy frecuente de tratarle de mentiroso, a pesar del esfuerzo de este último en ser muy fiel a sus percepciones de lo acontecido. Limitémonos en remitir al texto ineludible al respecto de Van Gijseghem (1990), sobre el testimonio del niño 
en un juicio, después de un abuso sexual, que debería ser una referencia básica para cualquier profesional de la Justicia.

Lo trágico es que un niño que no haya sido escuchado de manera adecua$\mathrm{da}$, es decir como sujeto de su hablar, vuelve al encierro del silencio, casi sin posibilidad de reanudar con los adultos una relación de confianza, fundada en palabras humanizantes.

\section{Para concluir: evitar la revictimización institucional no es ta- rea tan difícil}

A la luz de la investigación, la revictimización institucional aparece como moneda común en la atención a los casos de violencia contra niños, niñas y adolescentes, después de la denuncia de alguna forma grave de abuso sexual. Refleja la descoordinación de las intervenciones institucionales que no participan a la implementación de una política proactiva para el abordaje de estos casos.

Esta situación se explica sobre todo por el rechazo adulto de cualquier forma de responsabilización respecto a problemas cuya dinámica le resulta oscura, tanto como por las carencias en la formación de los intervinientes en el campo de la infancia. Esta falencia se observa en todos los niveles de atención, aunque tal vez con más nitidez en la función judicial (y la policía) - en la actualidad, no existen ni abogados ni jueces especializados en el trato con menores (Dupret, 2012).

A este aspecto, cabe añadir el temor de muchos adultos por dejarse involucrar en dramas familiares escondidos detrás de la mayoría de los casos de abuso sexual y maltrato grave contra menores, como si no tuvieran la fuerza personal para lidiar con los demonios de la humanidad y teman ser parte de esto mismo que cuestionan (Crivillé, 1986).

Por otro lado, el debate ético alrededor de problemáticas que tengan que ver con la niñez, la adolescencia o la familia, en especial en referencia a las cuestiones legales y de justicia, sufre en este momento un desgaste que deja a muchos en el desamparo. Sin ahondar este aspecto, hay que reconocer la fuerza de los discursos posmodernos que llevan a la mayoría a poner en duda sus valores esenciales porque se cree en la obligación a adherir al consenso general y no se 
atreve a ningún planteamiento crítico, dificulta la toma de posición en temas de actualidad, como, en lo que estamos hablando, a la familia. Se plantea entonces la cuestión que, es ¿a partir de cuándo está autorizada la función pública a intervenir respecto a las vivencias de un niño dentro de la familia?

Este mismo problema se refleja muy a menudo en la confusión de la problemática de las mujeres -y del llamado género- con la de los menores; porque no hay duda que una mujer adulta no es ni una niña, ni una adolescente, y por ende es una persona capaz de responsabilizarse por sí misma, al contrario de un menor que está en una relación de dependencia estructural con los adultos y cuyo crecimiento está moldeado por los ideales manejados por aquellos.

Al final de este ensayo, para responder a la pregunta que nos convoca: ¿cómo evitar la revictimización institucional?, podemos sintetizar la respuesta en tres puntos:

1. Coordinación de las intervenciones interdisciplinarias

2. Formación de los profesionales en cada una de las especialidades

3. Nombramiento de un responsable para el acompañamiento de cada caso Además, cabe reiterar el llamado urgente a la creación de espacios de atención psicosocial integral al lado de cada centro de salud, espacios que no se limiten a una mera oficina sino que presenten una verdadera capacidad de atención transdisciplinaria.

Una última recomendación. Cuando se interviene desde una Institución respecto a una situación de abuso sexual, más allá de cualquier otra consideración, es imperativo escoger, entre todas las opciones de intervención de las cuales se dispone, la que no propicie una nueva agresión contra el menor, la que tome más en cuenta sus necesidades esenciales y su bienestar (superior, como se enuncia en el Código de la Niñez y Adolescencia). En ninguna circunstancia, se justifica un procedimiento que perjudique al niño, a la niña o al adolescente en su equilibrio psíquico, mental y relacional, por lo más que responda a las exigencias del sistema social o judicial.

Evitar la revictimización no es, una tarea imposible sino que implica una voluntad política y ciudadana de devolver al menor su lugar en la sociedad, con respeto y también con responsabilidad, ya que el desarrollo no solo físico sino que también psíquico de las generaciones más jóvenes, depende por completo de la capacidad de los adultos en introducirles a un mundo más justo. 


\section{Bibliografía}

2000 "La entrevista única. INNFA y el programa Acción Ciudadana por la Ternura". En: Sistematización de las conferencias del equipo de San Diego y los protocolos para la atención en maltrato y abuso sexual infantil y adolescen-

Barudy, J. te. Quito: INNFA.

1998 El dolor invisible de la infancia. Buenos Aires: Paidós.

Coulborn Faller, K.

1993 Child Sexual Abuse: Intervention and Treatment Issues. U. S. Department of Health and Human Services Administration for Children and Families.

Crivillé, A.

1986 "Los profesionales frente a los padres que maltratan a sus hijos". II Congreso Latinoamericano sobre Maltrato al Menor. 16-21 de noviembre de 1985 Guayaquil-Ecuador.

Dupret, M. A.

2012 La violencia intrafamiliar contra niños y adolescentes ¿Cómo intervenir y cómo prevenir? Cuaderno/Investigaciones. Universidad Politécnica Salesiana. Quito: Abya-Yala.

Ferenczi, S.

1981[1933] Confusión de lengua entre los adultos y el niño.El lenguaje de la ternura y de la pasión. Tomo IV, pp. 139-149.

Haesevoets, Y. H.

2003 Regard pluriel sur la maltraitance des enfants. Vade mecum didactique. Bruxelles: Éditions Kluwer.

Piaget, J.

1960[1932] El criterio moral en el niño. Buenos Aires: Losada.

Unda, N.

2012 "Descripción y análisis de los casos de revictimización identificados por la oficina de atención a la ciudadanía del ministerio de justicia, derechos humanos y cultos en el período 2010-2011". Tesis de grado de la Maestría en Políticas Sociales de la Universidad Politécnica Salesiana, Quito.

Van Gijseghem, H.

1990 "Facteurs interférant avec la qualité du témoignage de l'enfant au tribunal dans des causes d'abus sexual". En: Revue canadienne de psycho-éducation. Vol. 19. No 1, pp. 11-22.

Envío 29 de octubre/2013 - Aceptación 17 de diciembre/2013 